\title{
Distributional patterns of soil nematodes in relation to environmental variables in forest ecosystems
}

\author{
Haifeng Xiao ${ }^{1,3}$, Wenting Wang ${ }^{1,4}$, Shangwen $\mathrm{Xia}^{1,2}$, Zhipeng $\mathrm{Li}^{1,4}$, Jianmin $\mathrm{Gan}^{1}$, Xiaodong Yang ${ }^{1,2, *}$ \\ 1 Key Laboratory of Tropical Forest Ecology, Xishuangbanna Tropical Botanical Garden, Chinese Academy of Sciences, \\ Xishuangbanna 666303, China \\ 2 Center of Plant Ecology, Core Botanical Gardens, Chinese Academy of Sciences, Xishuangbanna 666303, China \\ 3 College of Chemistry, Biology and Environmental Engineering, Xiangnan University, Chenzhou 423000, China \\ 4 University of Chinese Academy of Sciences, Beijing 100049, China
}

\section{H I G H L I G H T S}

- Relationships between environmental factors and nematode distributions at different spatial scales are assessed.

- Nematode diversity peaked in tropical forest ecosystem.

- Nematode diversity showed contrary patterns compared with their abundance.

- Factors most strongly affecting nematode communities changed across spatial scales.

\section{ARTICLE INFO}

Article history:

Received July 30, 2020

Revised September 23, 2020

Accepted October 15, 2020

Keywords:

Nematode communities

Spatial scales

Driving factors

High-throughput sequencing forest ecosystems
GRAPHICAL ABSTRACT

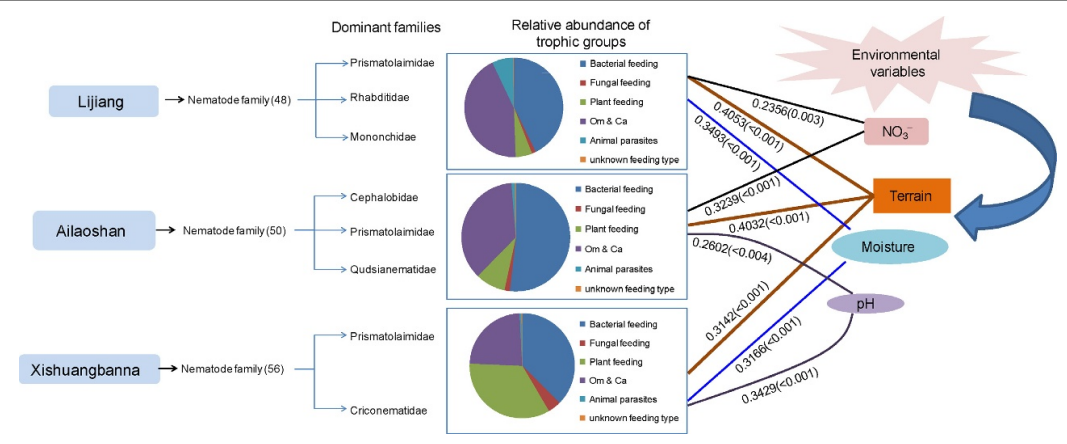

A B S T R A C T

Understanding biodiversity and biogeographic distribution of soil fauna is an important topic in ecology. While nematode communities have been compared among ecosystems, knowledge remains limited about how environmental factors and nematode distributions are linked at different spatial scales. Here, we employed high-throughput sequencing to compare nematode communities in tropical (Xishuangbanna), subtropical (Ailaoshan), and cold temperate spruce-fir (Lijiang) forest ecosystems with identical spatial sampling. Relationships between nematode communities and environmental factors were analyzed using redundancy analysis (RDA). Our results showed that nematode richness and diversity peaked in Xishuangbanna; however, no significant differences were observed in other two forest ecosystems. Bacterial feeders and Omnivores / Carnivores (Om \& $\mathrm{Ca}$ ) had the lowest relative abundance, but the highest diversity, in Xishuangbanna, with the opposite pattern being detected for fungal and plant feeders. Our data also demonstrated that, for forest ecosystems, climate factors drive nematode communities distributions at the regional scale, while terrain and soil characteristics (including $\mathrm{pH}$ and nutrients) drive nematode communities distributions at local scales. This study improves our current understanding of key factors (environmental parameters) responsible for the biogeographical distribution of forest nematode communities at different spatial scales.

(c) Higher Education Press 2020 


\section{Introduction}

A scientific understanding of biological distribution patterns across different spatial scales is required to explain relationships between aboveground and belowground biodiversity in terrestrial ecosystems (Wu et al., 2011). Global diversity patterns of plants and aboveground macroscopic vertebrates have been clarified (Porazinska et al., 2012). However, there is no evidence that the distribution patterns of belowground organisms, particularly microscopic soil animals (such as soil nematodes), are similar to aboveground organisms (Fierer et al., 2009; Decaëns, 2010; Bardgett and van der Putten, 2014). Our general understanding of distributional patterns of microscopic soil organisms and driving factors remains limited.

Nematodes are widely distributed, small-bodied soil metazoans that account for more than $80 \%$ of the abundance of animals on Earth (Fonseca et al., 2010). Their global species richness is tentatively predicted to exceed 1 million (Lambshead, 2004). Besides their huge numbers and diversity, they occur in all ecosystems, with various feeding types in food webs and functional diversity; consequently, they act as important bio-indicators, with key roles in mediating ecosystem processes (Bongers and Ferris, 1999; Neher, 2010). Therefore, by understanding the distributional patterns of soil nematodes, we could advance our knowledge of biogeography and ecology.

Soil nematodes often show high abundance and diversity at local scales (Boag and Yeates, 1998; Yeates, 1999). For example, Lawton et al. (1998) collected 374 species from a tropical forest in Cameroon, while Bloemers et al. (1997) reported 200 individuals and 89 nematode species in a single 1.9-cm diameter soil core. However, nematode distributions at larger scales have received relatively less attention (Nielsen et al., 2014; Song et al., 2017; van den Hoogen et al., 2019). Nielsen et al. (2014) showed the macro-ecological patterns and limited distribution of some nematode families at a global scale. A recent study showed that nematode abundance peaked in high-latitude zones rather than low-latitude zones in a global study (van den Hoogen et al., 2019). For nematode diversity study, Boag and Yeates (1998) found nematode communities to be less diverse in tropics than temperate ecosystems, while Powers et al. (2009) and Porazinska et al. (2010) obtained contrasting results. Other studies reported minimal differences in nematodes alpha diversity, even between Arctic and tropical regions (Kerfahi et al., 2016; Song et al., 2017). These inconsistent results demonstrate that knowledge of soil nematode distributions at large scales remains incomplete. Moreover, few comparisons of trophic groups and their driving factors have been completed at regional scales (Porazinska et al., 2012).

The geographical distributions of nematodes might be affected by many factors, including climate (temperature, rainfall), soil properties ( $\mathrm{pH}$, nutrients), and vegetation types (Harrison and Cornell, 2008). However, dominant controlling factors across spatial scales remain unclear (Bardgett and van der Putten, 2014). This phenomenon impedes our ability to predict the structure of nematode communities following environmental shifts. Nielsen et al. (2014) showed that nematode distributional patterns were strongly related to mean annual rainfall and temperature at the global scale, van den Hoogen et al. (2019) found that soil resource availability is a dominant factor driving the distribution pattern of nematode abundance. At local scale, the dominant driving factors may be changed to factors including soil organic matters (Chen et al., 2015), $\mathrm{pH}$ (Liang et al., 2005), texture (Salame and Glazer, 2015) or other factors. Because spatial scale is inextricably linked with environmental heterogeneity, compared to small scales, larger spatial areas generally lead to greater environmental heterogeneity (Feeser et al., 2018). Thus, it is important to clarify the different driving factors at different spatial scales.

As molecular approaches have become an increasingly important tool to assess the diversity of soil fauna (Du et al., 2020), here, we employed the Illumina Miseq DNA platform to investigate the nematode communities of three distinct forest ecosystems. The first was a fast turn-over tropical forest (Xishuangbanna) that had little plant litter persisting on soil surfaces. The other two were humus-rich subtropical (Ailaoshan) and temperate forests (Lijiang) with high soil organic matter content (Chan et al., 2006; Qiao et al., 2014). We tested the hypothesis that nematode diversity is ordered tropical>subtropical>temperate, because aboveground plant species is highest in Xishuangbanna, followed by Ailaoshan and Lijiang (Lan et al., 2008; Huang et al., 2017; Wen et al., 2018). In addition we tested whether the relative abundance of different nematode trophic groups was closely related to their available resources. We also examined whether nematode distributions at regional scales corresponded to climatic differences (Nielsen et al., 2014), and whether those at local scales corresponded to soil properties. Specifically, we evaluated: 1) how the nematode community (diversity and trophic groups) differed among tropical, subtropical, and temperate forest ecosystems, 2) examined the distributional patterns of soil nematodes by analyzing the relationships between nematode community and environmental factors in forest ecosystems at both regional and local scales.

\section{Materials and methods}

\subsection{Experimental design}

We sampled soils from three CTFS forest plots in long-term ecological experimental stations of the Chinese Academy of Sciences in Yunnan Province, China; specifically: 1) 20-ha Xishuangbanna Forest Dynamics Plot (FDP) $\left(21^{\circ} 36^{\prime} \mathrm{N}\right.$, $\left.101^{\circ} 34^{\prime} \mathrm{E}\right)$, 2) 20 -ha Ailaoshan FDP (243' $\left.\mathrm{N}, 102^{\circ} 01^{\prime} \mathrm{E}\right)$, and 3) 25-ha Lijiang FDP ( $\left.27^{\circ} 10^{\prime} \mathrm{N}, 100^{\circ} 13^{\prime} \mathrm{E}\right)$. Xishuangbanna is a typical Asian Monsoonal seasonal tropical rainforest that has two distinct climates; namely, the wet season (from May to October) and dry season (from November to April). The elevation ranges from 708 to 869 
$\mathrm{m}$, with a mean annual precipitation of $1493 \mathrm{~mm}$, of which $1256 \mathrm{~mm}(84 \%)$ occurs in the wet season. The annual average temperature is $21.8^{\circ} \mathrm{C}$ (Cao et al., 2006). The Ailaoshan FDP is an evergreen broadleaved forest that has an annual mean precipitation of $1931 \mathrm{~mm}$, of which $85 \%$ occurs between May and October. Elevation within the FDP ranges from 2490 to $2530 \mathrm{~m}$, with an annual average temperature of $11.3^{\circ} \mathrm{C}$ (Gong et al., 2011). The Lijiang FDP is a cold temperate spruce-fir forest that has an annual mean precipitation of $1587 \mathrm{~mm}$. The elevation within the FDP ranges from 3220 to $3344 \mathrm{~m}$, with annual average temperature of $5.5^{\circ}$ C (Huang et al., 2017).

At each forest dynamics plot, we established three $20 \mathrm{~m} \times$ $20 \mathrm{~m}$ square sub-plots that were at least $50 \mathrm{~m}$ apart. At each station, one of the three $20 \mathrm{~m} \times 20 \mathrm{~m}$ plots was on sloped land, while the other two were on flat ground and near ravines. Each plot was separated into sixteen $5 \mathrm{~m} \times 5 \mathrm{~m}$ quadrats (Fig $\mathrm{S} 1)$. In each $5 \mathrm{~m} \times 5 \mathrm{~m}$ quadrat, five soil samples were taken (one in the middle four at the corners) from 0 to $15 \mathrm{~cm}$ depth using a 5-cm diameter soil corer after removing surface plant litter. These cores were combined as independent replicates. Thus, in nine $20 \mathrm{~m} \times 20 \mathrm{~m}$ plots, each plot had sixteen $5 \mathrm{~m} \times$ $5 \mathrm{~m}$ quadrats, from which 144 separate soil samples were collected. Each of these soil samples was separated into two parts. One part was used to analyze physical and chemical properties (soil moisture, total $\mathrm{C}, \mathrm{N}$, and $\mathrm{pH}$ ). The other part was used to extract soil nematodes. Soil nematodes were collected by combined sucrose centrifugation and Baermann funnels. In brief, $100 \mathrm{~g}$ fresh soil was weighed, and was then placed in Baermann funnels to extract soil nematodes for $48 \mathrm{~h}$. After this, the soil was not discarded, rather $100 \mathrm{~mL}$ sucrose solution ( $454 \mathrm{~g} \mathrm{~L}^{-1}$ of water) was added for additional centrifugation and further extraction (McSorley and Frederick, 2004). Finally, extracts were immediately used for subsequent DNA extraction.

\subsection{Genetic sequencing}

High-throughput sequencing was performed as follows: first, nematode genomic DNA was extracted using a Power Soil ${ }^{\circledR}$ DNA Isolation Kit (MO BIO) according to the supplied instructions. Primers (NF1:5'GGTGGTGCATGGCCGTTCTTAGTT3' 18sr2b:5'TACAAAGGGCAGGGACGTAAT3'; Porazinska et al., 2012), including an eight base index, were synthesized. PCR involved an initial 4 min denaturing step at $94^{\circ} \mathrm{C}$, followed by 35 cycles of denaturation at $94^{\circ} \mathrm{C}$ for $30 \mathrm{~s}$, annealing at $55^{\circ} \mathrm{C}$ for $30 \mathrm{~s}$, extension at $72^{\circ} \mathrm{C}$ for $45 \mathrm{~s}$, with a final extension at $72^{\circ} \mathrm{C}$ for $5 \mathrm{~min}$. The target PCR amplified product size was about $400 \mathrm{bp}$. Purified PCR products were used to build the library, followed by sequencing with Illumina Miseq (Read Length $2 \times 300 \mathrm{bp}$ ). Bidirectional sequences generated by Miseq were spliced by FLASH software. After removing chimeras with QIIME, high-quality sequences were assigned to each sample by split_libraries.py program in QIIME. Finally, these sequences were blasted in the SILVA 119SSUParc (www.arb-silva.de) database (Quast et al. 2013). We chose this database because our primers were
SSU rRNA loci flanked. In addition, this database has more than four million high-quality eukaryotic 16/18S rRNA sequences, including nearly 20000 nematode reference sequences. The closest matching sequence contained in the database, for which taxonomic information was documented, was used for the subsequent analysis.

All matched sequences in the SILVA 119SSUParc database were assigned a species identity. For more accuracy, we used Statistical Assignment Package (SAP) to evaluate taxonomic accuracy (Munch et al., 2008). This method is used to assign posterior probabilities at each taxonomic level. Here, we set it to $85 \%$ to estimate reliability at each taxonomic level. For 1000 randomly selected nematode sequences, SAPs were successfully assigned all sequences at $34 \%$, $55 \%, 86 \%$, and $99 \%$ for species, genus, family, and order taxonomic levels, respectively. This result suggests that SILVA assignments below the family level should be treated with low confidence ( $<85 \%$ posterior probability). Thus, only family and order taxonomic information were used for further analysis. We only used family taxonomic information for the analysis. Nematode families were grouped according to trophic status (bacterial-feeders, fungal-feeders, plant feeders, omnivores, and carnivores) following Yeates et al. (1993) and the website nemaplex.ucdavis.edu.

\subsection{Statistical analysis}

A linear mixed-effects model was used to analyze the effects of terrain and sites on nematode diversity (Shannon-Wiener diversity index $H^{\prime}=-\sum p_{i}\left(\ln p_{i}\right)$, where $p_{i}$ is the proportion of reads in the ith taxon) and richness among Xishuangbanna, Ailaoshan, and Lijiang FDPs. Duncan's test was used to determine if differences were significant, with significance being set at $P<0.05$. Soil moisture, $\mathrm{pH}, \mathrm{C}: \mathrm{N}, \mathrm{NH}_{4}{ }^{+}$, and $\mathrm{NO}_{3}$ was used to construct a soil property and terrain matrix for redundancy analysis (RDA) in the vegan package (Oksanen et al., 2010) of R v. 1.17-3 project (R Development Core Team, 2013). Detrended correspondence analysis (DCA) indicated that axis length was less than three; thus, redundancy analysis (RDA) was appropriate to analyze relationships between nematode communities and edaphic factors. The function adonis in $\mathrm{R}$ was used to compare differences in the nematode community among Xishuangbanna, Ailaoshan, and Lijiang FDPs, and among plots in each FDP. The function envfit was used to detect correlative significance between each environmental variable and the nematode community.

\section{Results}

\subsection{BLAST results of sequences}

The 144 soil samples yielded a total of 2240769 high-quality sequences, of which 643119 sequences were from Xishuangbanna FDP, 607128 sequences were from Ailaoshan FDP, and 990522 sequences were from Lijiang FDP. For Xishuangbanna FDP, only 137245 (21.3\%) sequences were identified 
as soil nematodes. For Ailaoshan FDP, 368647 (60.7\%) sequences were identified as soil nematodes. For Lijiang FDP, $638314(64.4 \%)$ sequences were identified as soil nematodes, based on BLAST results. All nematode sequences combined represented 56 families from 15 orders. In addition to soil nematodes, other sequences were identified as eukaryotic taxa, representing nine phyla (Table S1)

The trophic groups of soil nematodes differed among the three forests. The relative abundance of bacterial-feeding $(37.37 \%)$ and plant-feeding groups $(34.53 \%)$ was similar in Xishuangbanna FDP, with both groups being dominant, followed by omnivores and carnivores and fungal feeders (Table S2). However, in Ailaoshan FDP, the bacterial-feeding group $(51.78 \%)$ was overwhelmingly dominant, followed by omnivores and carnivores, plant feeders, and fungal feeders (Table S2). Both bacterial-feeding group (42.73\%) and Omnivores \& Carnivores (Om \& Ca) $(43.46 \%)$ were dominant in Lijiang FDP, followed by animal parasites, plant feeders, and finally fungal feeders (Table S2).

\subsection{Diversity of soil nematodes}

A total 56, 50, and 48 nematode families were detected in Xishuangbanna, Ailaoshan, and Lijiang FDP, respectively. Prismatolaimidae and Criconematidae were the dominant (more than 10\%) families in Xishuangbanna; Cephalobidae, Prismatolaimidae, and Qudsianematidae were the dominant families in Ailaoshan FDP; and Prismatolaimidae, Rhabditidae, and Mononchidae were the dominant families in Lijiang FDP (Table S2). Significant differences in nematode family richness were detected in these three forest ecosystems $\left(F_{\text {sites }}=32.083^{* *}\right)$, of which Xishuangbanna FDP had the highest diversity; however, no significant difference was observed between Ailaoshan and Lijiang FDP (Fig. 1A). Nematode diversity showed a very similar pattern to richness $\left(F_{\text {sites }}=29.225^{* *}\right.$, Fig. 1B). The high diversity in Xishuangbanna FDP was mostly generated by bacterial-feeding soil nematodes (Fig. 2).

3.3 Communities of soil nematodes within forest dynamic plot (FDP)

At the regional scale, significant nematode community differences were observed among Xishuangbanna, Ailaoshan, and Lijiang FDP $\left(F_{\text {sites }}=54.196^{* * *}, F_{\text {terrain }}=\right.$ 4.863*** Fig. 3). Soil C:N and moisture were the main drivers that influence the nematode community composition (Table S3).

At the local scale of each FDP (Fig. 4), different factors affect the nematode distribution in different plot. In the Xishuangbanna FDP, $\mathrm{pH}$, moisture, and terrain were the main factors that influence the nematode community composition (Table S4). In the Ailaoshan FDP, terrain, $\mathrm{NO}_{3}{ }^{-}$and $\mathrm{pH}$ were the main factors (Table S4). In the Lijiang FDP, moisture, terrain and $\mathrm{NO}_{3}{ }^{-}$were the main factors that influence the nematode community composition (Table S4).
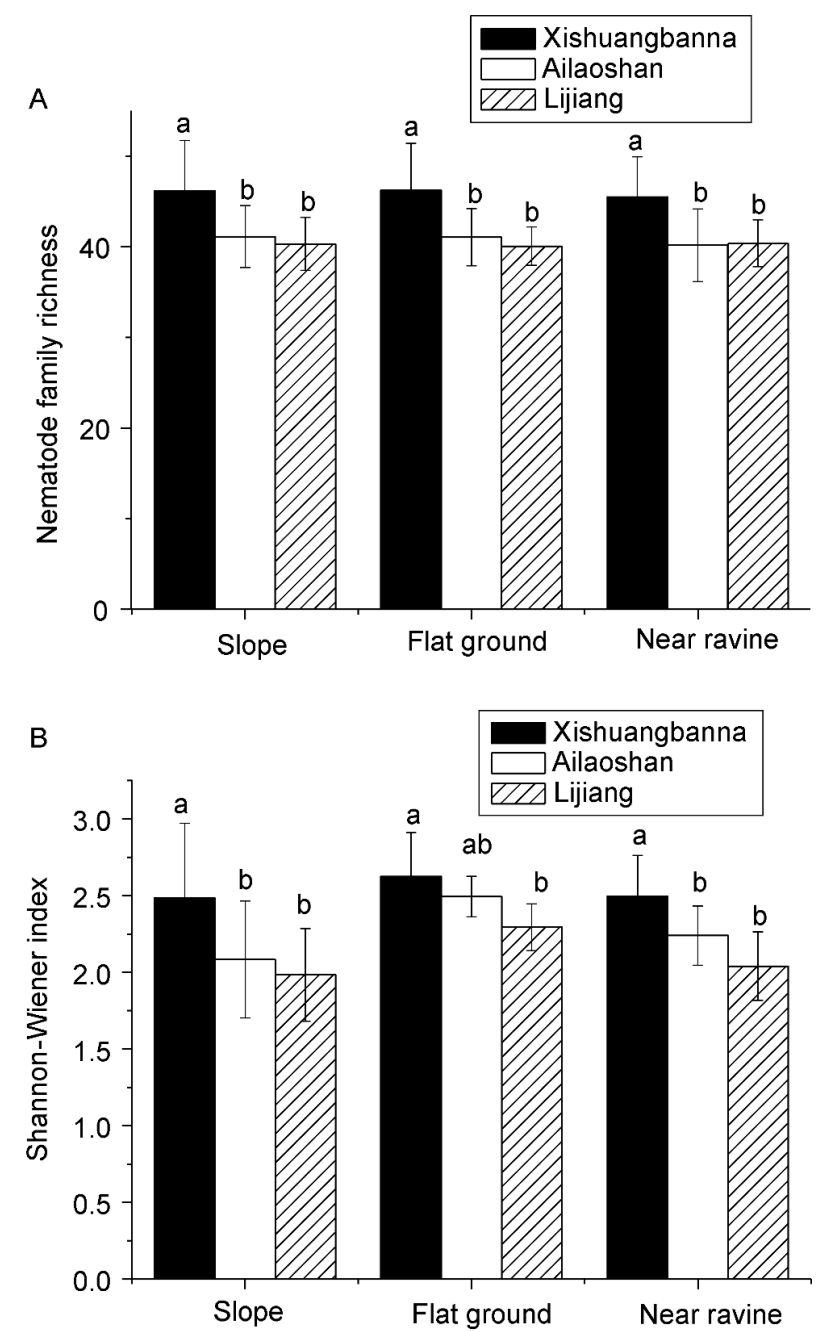

Fig. 1 Nematode family richness (A) and diversity (B) at different terrain conditions in Xishuangbanna, Alilaoshan and Lijiang FDPs. Error bars represent standard deviation $(n=16)$. Lower case letters indicate significant differences $(P<0.05$, Duncan's test) among Xishuangbanna, Alilaoshan and Lijiang FDPs.

\section{Discussion}

\subsection{Nematode richness and diversity}

Previous studies on soil nematode richness and diversity detected two contrasting trends. Some studies in the 1980s and 1990s found that nematode diversity was augmented by increasing latitude (Procter, 1984; Boucher, 1990; Boucher and Lambshead, 1995); however, studies in the 2000s showed that nematode richness and diversity follow no definite trend along a latitudinal gradient (Boag and Yeates, 1998; Fonseca and Netto, 2015; Song et al., 2017). Our findings were consistent with those of by Yeates (1999), with soil nematodes exhibiting greater diversity at lower latitudes. Our study showed that soil nematode richness and the Shannon-Wiener diversity index were higher in tropical forest 

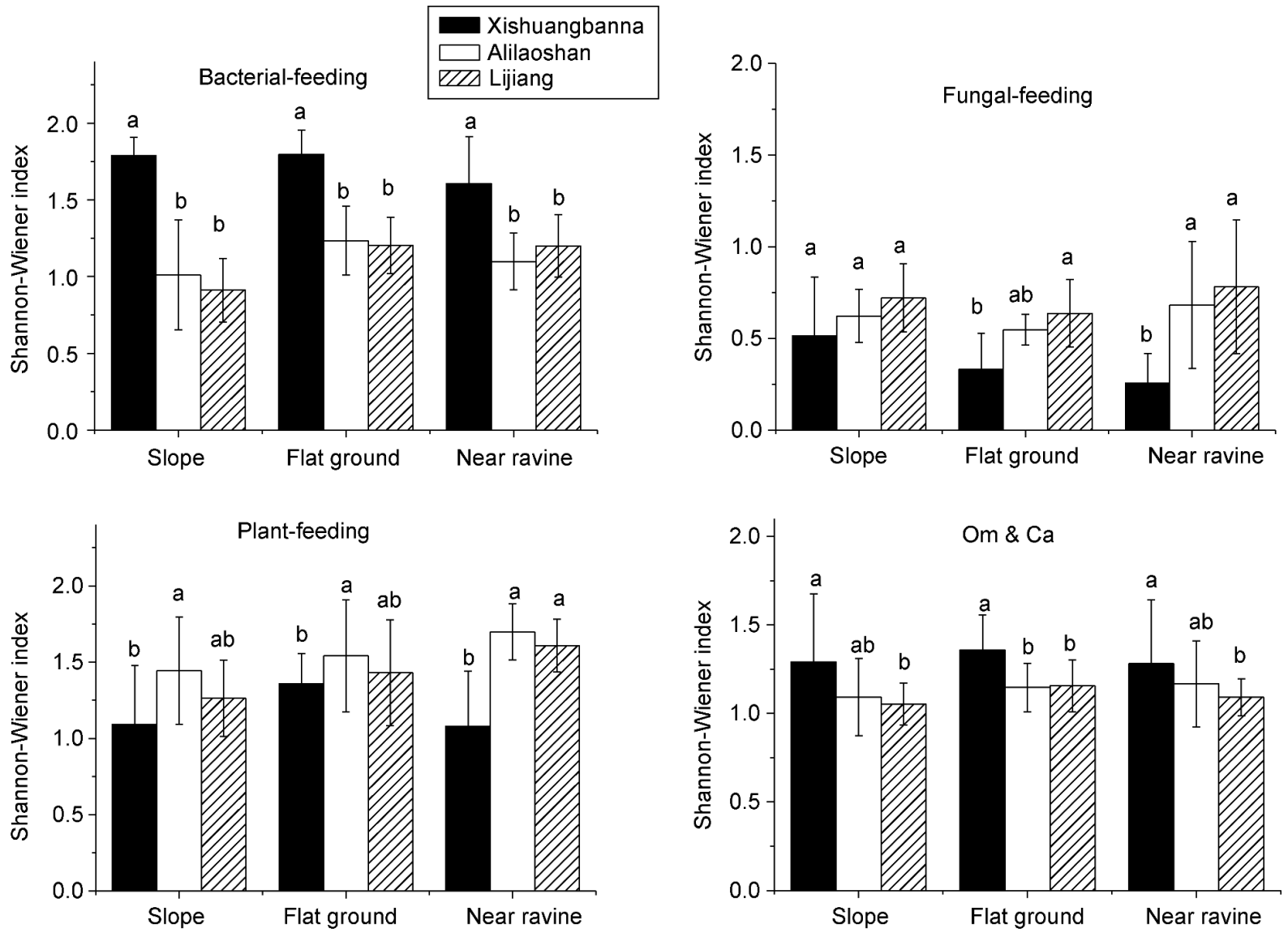

Fig. 2 Shannon-Wiener Index of different soil nematodessoil soil nematodes feeding types at different terrain conditions in Xishuangbanna, Alilaoshan and Lijiang FDPs. Error bars represent standard deviation $(n=16)$. Lower case letters indicate significant differences $(P<0.05$, Duncan's test) among Xishuangbanna, Alilaoshan and Lijiang FDPs.

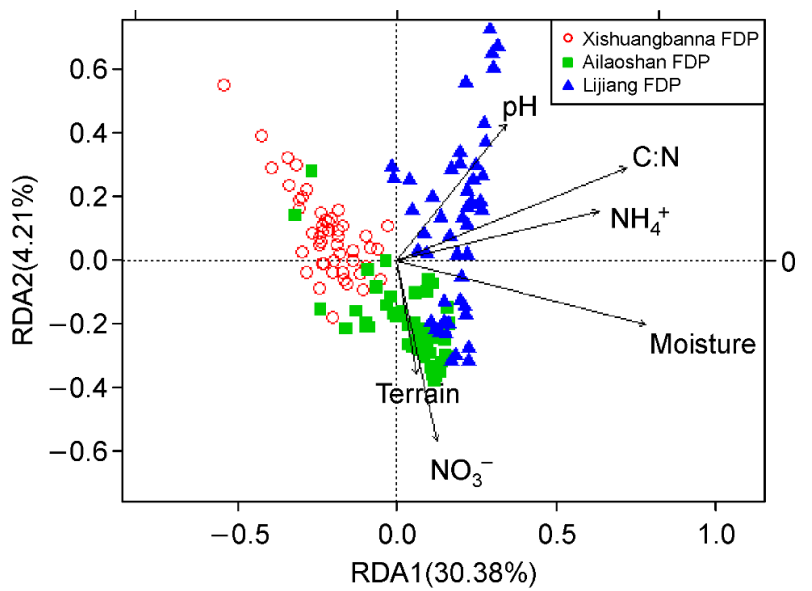

Fig. 3 Redundancy analysis (RDA) of the nematode family communities and relationships between nematode communities and environmental variables with symbols coded by study sites in Yunnan Province, China.

(Xishuangbanna FDP) compared to the other two ecosystems viz. subtropical (Ailaoshan FDP) and temperate forest (Lijiang FDP). This result supports previous studies and demonstrated that tropical forests had higher soil nematode diversity than temperate forests (Porazinska et al., 2010; Porazinska et al., 2012).

Despite Xishuangbanna (tropical site) having the highest richness and diversity of nematodes, no significant difference was observed between Ailaoshan and Lijiang. Although different climate conditions was observed between Ailaoshan and Lijiang FDP (annual average temperature is $10.7^{\circ} \mathrm{C}$ and $5.5^{\circ} \mathrm{C}$ in Ailaoshan and Lijiang FDP respectively; Huang et al., 2017; Wen et al., 2018), both of them have thick humus and high organic carbon content (Table 1). Similar soil characteristics may be an important reason for the lack of significant differences in nematode richness and diversity. The pattern of belowground richness and diversity such as soil nematodes is very complex, and is strongly influenced by soil physicochemical properties, rather than climate variables (Bardgett and van der Putten, 2014).

\subsection{Trophic distribution patterns of soil nematodes}

Most existing studies identified nematode trophic groups based on microscopic identification, which is very time consuming and labor intensive when large samples must be analyzed, and requires professional expertise for identification. Molecular methods allowed us to estimate the relative 

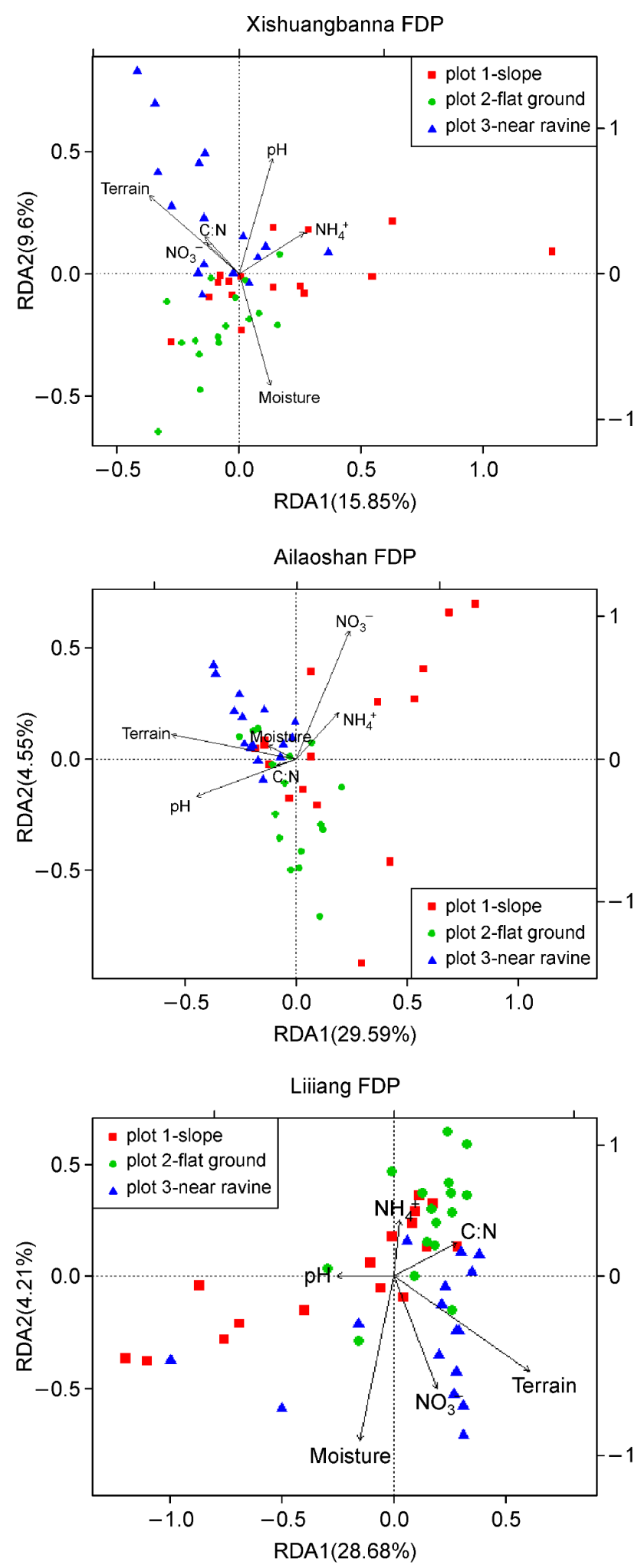

Fig. 4 Redundancy analysis (RDA) of the nematode family communities and relationships between nematode family communities and environmental variables with symbols coded by terrain in Xishuangbanna and Ailaoshan FDPs, Yunnan Province, China. abundance of nematodes from large sample sizes rapidly, however, limitations exist. For instance, Molecular methods cannot do quantitative analysis. In addition, blast results tend to have low taxonomic resolution. Soil nematodes of larger body size also tend to be overestimated, as they have more cells and gene copies per individual, increasing their component in DNA-sequence analyses (Griffiths et al., 2006). Even so, using the number of sequences to reflect the relative abundance of nematode species has potential. For instance, Porazinska et al. (2010) showed that the number of individuals per nematode species was closely correlated with read abundance. Du et al. (2000) compared morphological and high-throughput sequencing methods and found that the two methods reached consistent conclusions in the nematode community composition and trophic structure.

The trophic abundance of soil nematodes is generally best explained by substrate resources. Our data (C and N) supported previous studies, showing that subtropical (Ailaoshan FDP) and temperate forest (Lijiang FDP) had much more soil organic matter and, hence, likely to support more microbial biomass (Chan et al., 2006; Qiao et al., 2014), and it is also confirmed by other evidence. For example, Qiao et al. (2004) found that microbial biomass carbon in subtropical forest (Ailaoshan FDP) was approximately five times greater than that in tropical forest (Xishuangbanna FDP). Interestingly, Chan et al. (2006) showed that the total microbial biomass of the surface organic layer at Ailaoshan FDP $\left(4.33 \pm 1.64 \mathrm{~g} \mathrm{C} \mathrm{kg}^{-1}\right.$ dry soil) was approximately twofold greater than that of surface mineral soil $\left(2.16 \pm 0.88 \mathrm{~g} \mathrm{C} \mathrm{kg}^{-1}\right.$ dry soil) in Xishuangbanna FDP. However, the surface mineral soil of Xishuangabanna FDP contained three times less microbial biomass $\left(0.63 \pm 0.17 \mathrm{~g} \mathrm{C} \mathrm{kg}^{-1}\right.$ dried soil) than that Ailaoshan FDP. Therefore, it is reasonable for Ailaoshan and Lijiang FDP support a higher relative abundance of bacterialfeeding nematodes (Table S2). Likewise, the higher relative abundance of plant-feeding nematodes at Xishuangbanna FDP might reflect the high plant diversity, because certain plant roots are susceptible to soil nematodes feeding on them (Liu et al., 2002; Zheng et al., 2006; De Deyn et al., 2008; Xiao et al., 2014; Zhang et al., 2015; van den Hoogen et al., 2019). For example, Zhang et al. (2015) showed that tropical rainforests have the highest root biomass than other forest types based on estimates of the root biomass of 11 forest types in China. The relative abundance of plant-feeding and bacterial-feeding nematodes in this study was consistent with that of Nielsen et al. (2014), who found that plant-parasitic dominate warm sites, while bacterial feeders dominate colder sites. This distribution pattern could be explained by the fact that more plant biomass resources are available for parasites to exploit in tropical forests. Alternatively, colder sites might be more disturbed, allowing opportunistic bacterial feeders to dominate (Bongers and Ferris, 1999; Nielsen et al., 2014). Our results also showed that the abundance of Om \& Ca was relatively higher in sub-tropical and temperate forest (Ailaoshan and Lijiang FDPs) compared to tropical forest 
ecosystem (Xishuangbanna FDP). This phenomenon might be related to more humus or organic matter accumulating in sub-tropical and temperate forest, as organic $\mathrm{C}$ is an important growth factor determining nematode body size, especially for large-bodied Om \& Ca (Liu et al., 2015). In addition, more large-bodied soil nematodes were observed in sub-tropical and temperate forest (Ailaoshan and Lijiang FDPs) than in tropical forest (Xishuangbanna FDP) when we extracted soil nematodes from soil samples. Of note, we cannot rule out that this high proportion of $\mathrm{Om} \& \mathrm{Ca}$ in sub-tropical and temperate forest may be caused by their larger body size.

For nematode trophic diversity (Fig. 2), all four trophic types showed contrasting patterns to the relative trophic abundance of soil nematodes for tropical forest versus the other two forest ecosystems. Thus, higher abundance does not necessarily indicate higher diversity. For example, in the current study, tropical forest (Xishuangbanna FDP) had the highest relative abundance $(34.12 \%)$ but the lowest diversity of plant feeders than the other two forest ecosystems. This contrasting trophic diversity of soil nematodes implies that available food resources differ across forest ecosystems.

4.3 The factors driving variation of soil nematode community at different spatial scales

The nematode community is related to environmental factors at different scales (Boag and Yeates, 1998; Nielsen et al., 2014). Similarly, our data showed small overlaps that indicated significant differences to the nematode community among the three forest types (Xishuangbanna, Ailaoshan and Lijiang FDPs) (Fig. 3). Both $\mathrm{C}: \mathrm{N}$ and moisture were the strongest factors contributing to this difference (Table S3). The higher latitude and elevation at Ailaoshan FDP (approximately $2500 \mathrm{~m}$ ) and Lijiang FDP (approximately $3200 \mathrm{~m}$ ) compared to Xishuangbanna FDP (approximately $800 \mathrm{~m}$ ) resulted in these two sites having lower temperatures and slower decomposition rates, with greater humus accumulation (Huang et al., 2007; van den Hoogen et al., 2019). This humus accumulation inevitably causes higher organic $\mathrm{C}$ and $\mathrm{C}: \mathrm{N}$ in these two forest ecosystems (Table 1). In addition, the surface soils of these two systems are less dense with higher water content (up to $60 \%-70 \%$, Table 1) than in Xishuangbanna FDP (approximately 30\%). Given that C:N and soil moisture are important factors affecting nematode communities, they are also the strongest factors driving differences in nematode communities (van den Hoogen et al., 2019). Differences in $\mathrm{C}: \mathrm{N}$ and soil moisture among the three studied forest ecosystems was driven by differences in temperature; thus, climate factor likely determine the composition of nematode communities at regional scales. However, the influences of climate on soil nematodes are not direct, but act indirectly by changing soil conditions (van den Hoogen et al., 2019).

The current study delineated three distinct groups within each forest dynamic plot (FDP), which were based on terrain dimensions viz. slope, flat ground, and proximity to ravines (Fig. 4). Thus, environmental heterogeneity caused by spatial distance (at least $50 \mathrm{~m}$ between plots in this study) significantly contributes toward determining patterns in the spatial distribution of the nematode community at the habitat scale (Bardgett and van der Putten, 2014). Of importance, this terrain-based pattern was similar at all the three study sites (Lijiang, Ailaoshan, and Xishuangbanna FDPs). Terrain was the only factor that significantly drove differences in the nematode community at all three FDPs (Fig. 4). This phenomenon was probably caused by soil nematodes responding to variation in soil properties that was reflected by terrain rather than a response to terrain, per se. For example, more litterfall accumulates on flat ground compared to slopes, and is considered to have an important impact on soil nutrients (Xia et al., 2015), which affect nematode communities. Furthermore, soil $\mathrm{pH}$ was the main factor determining differences to the nematode communities between tropical forest (Xishuangbanna FDP) and subtropical forest (Ailaoshan FDP). In comparison, $\mathrm{NO}_{3}{ }^{-}$determined differences in the nematode communities between subtropical forest (Ailaoshan FDP) and temperate forest (Lijiang FDP). Thus, terrain and soil properties, rather than climate factors (like temperature) drive the distribution of soil nematodes at local scales. This phenomenon is consistent with our hypothesis, and supports the conclusions of Bardgett and van der Putten (2014); specifically, at large spatial scales, climatic and topographic factors strongly influence the distribution of biodiversity in soils, the physical and chemical properties of soils are more important factors at smaller scales.

\section{Conclusions}

The current study confirmed that the diversity and patterns of distribution of small invertebrates do not completely follow that of above-ground plants or large animals; however, invertebrate diversity was highest in the low latitude tropical forest. The relative abundance of nematode trophic groups showed contrasting patterns with diversity in this study. Lower temperatures (which reduce decomposition rates) and accumulated surface organic matter were dominant factors

Table 1 Forest topsoil $(0-15 \mathrm{~cm})$ total $\mathrm{C}, \mathrm{N}, \mathrm{pH}$ and water content in Xishuangbanna, Ailaoshan and Lijiang FDP \pm represent deviation $(n=48)$.

\begin{tabular}{lllll}
\hline Sites & Total carbon $\left(\mathrm{g} \mathrm{kg}^{-1}\right)$ & Total nitrogen $\left(\mathrm{g} \mathrm{kg}^{-1}\right)$ & $\mathrm{pH}$ & Water content $(\%)$ \\
\hline Xishuangbanna & $18.26 \pm 2.79$ & $2.05 \pm 0.24$ & $5.03 \pm 0.30$ & $29.87 \pm 2.54$ \\
Ailaoshan & $64.87 \pm 4.72$ & $6.40 \pm 0.51$ & $4.84 \pm 0.15$ & $66.26 \pm 2.49$ \\
Lijiang & $85.64 \pm 5.97$ & $6.9 \pm 0.63$ & $5.44 \pm 0.47$ & $74 \pm 2.91$ \\
\hline
\end{tabular}


affecting the distribution of soil nematodes in these three FDPs. Therefore, climate appears to be the most important factor influencing the distribution of soil nematodes at regional scales. However, at local scales, terrain and soil properties were the most important factors; therefore, the factors that have the strongest effect on nematode communities vary across different spatial scales. In conclusion, this study clarifies how soil nematodes are distributed in forest ecosystems across large spatial scales, and could be applied to predictions in other regions.

\section{Acknowledgments}

This work was supported by South-east Asia Biodiversity Research Institute, Chinese Academy of Sciences (Y4ZK111B01), the CAS 135 program (2017XTBG-T01) and the Hunan Provincial Natural Science Foundation of China (No. 2020JJ4564). We thank Xishuangbanna Station for Tropical Rainforest Ecosystem Studies the Ailaoshan forest ecosystem research stations of the Chinese Academy of Sciences, and Public Technology Service Center of Xishuangbanna Tropical Botanical Garden for providing support and experimental facilities. We thank Dr. Sandhya Mishra for providing comments and language assistance to improve this manuscript. Finally, thank the anonymous reviewers who helped to improve this manuscript. We would like to thank Editage (www. editage.cn) for English language editing.

\section{Data accessibility}

The nematode SSU RNA gene sequences recovered in this study were deposited in the NCBI GenBank Sequence Read Archive (SRA) under accession number SRP074446.

\section{Electronic supplementary material}

Supplementary material is available in the online version of this article at http://dx.doi.org/10.1007/s42832-020-0069-8 and is accessible for authorized users.

\section{References}

Bardgett, R.D., van der Putten, W.H., 2014. Belowground biodiversity and ecosystem functioning. Nature 515, 505-511.

Bloemers, G.F., Hodda, M., Lambshead, P.J.D., Lawton, J.H., Wanless, F.R., 1997. The effects of forest disturbance on diversity of tropical soil soil nematodessoil soil nematodes. Oecologia 111, 575-582.

Boag, B., Yeates, G.W., 1998. Soil nematode biodiversity in terrestrial ecosystems. Biodiversity and Conservation 7, 617-630.

Bongers, T., Ferris, H., 1999. Nematode community structure as a bioindicator in environmental monitoring. Trends in Ecology \& Evolution 14, 224-228.

Boucher, G., 1990. Pattern of nematode species - diversity in temperate and tropical subtidal sediments. Marine Ecology (Berlin) 11, 133-146.
Boucher, G., Lambshead, P.J.D., 1995. Ecological biodiversity of marine soil nematodessoil soil nematodes in samples from temperate, tropical, and deep-sea regions. Conservation Biology 9, 1594-1604.

Cao, M., Zhou, X.M., Warren, M., Zhu, H., 2006. Tropical forests of Xishuangbanna, China. Biotropica 38, 306-309.

Chan, O.C., Yang, X.D., Fu, Y., Feng, Z., Sha, L., Casper, P., Zou, X., 2006. 16S rRNA gene analyses of bacterial community structures in the soils of evergreen broad-leaved forests in south-west China. FEMS Microbiology Ecology 58, 247-259.

Chen, D., Cheng, J., Chu, P., Hu, S., Xie, Y., Tuvshintogtokh, I., Bai, Y., 2015. Regional-scale patterns of soil microbes and nematodes across grasslands on the Mongolian plateau: relationships with climate, soil, and plants. Ecography 38, 622-631.

De Deyn, G., Cornelissen, J.H.C., Bardgett, R.D., 2008. Plant functional traits and soil carbon sequestration in contrasting biomes. Ecology Letters 11, 516-531.

Decaëns, T., 2010. Macroecological patterns in soil communities. Global Ecology and Biogeography 19, 287-302.

Du, X.F., Li, Y.B., Han, X., Ahmad, W., Li, Q., 2020. Using highthroughput sequencing quantitatively to investigate soil nematode community composition in a steppe-forest ecotone. Applied Soil Ecology 152, 103562.

Feeser, K.L., Van Horn, D.J., Buelow, H.N., Colman, D.R., McHugh, T. A., Okie, J.G., Schwartz, E., Takacs-Vesbach, C.D., 2018. Local and regional scale heterogeneity drive bacterial community diversity and composition in a polar desert. Frontiers in Microbiology 9, 1928.

Fierer, N., Strickland, M.S., Liptzin, D., Bradford, M.A., Cleveland, C. C., 2009. Global patterns in belowground communities. Ecology Letters 12, 1238-1249.

Fonseca, G., Netto, S.A., 2015. Macroecological patterns of estuarine soil nematodessoil soil nematodes. Estuaries and Coasts 38, 612 619.

Fonseca, V.G., Carvalho, G.R., Sung, W., Johnson, H.F., Power, D.M., Neill, S.P., Packer, M., Blaxter, M.L., Lambshead, P.J.D., Thomas, W.K., Creer, S., 2010. Second-generation environmental sequencing unmasks marine metazoan biodiversity. Nature Communications $1,98$.

Gong, H., Zhang, Y., Lei, Y., Liu, Y., Yang, G., Lu, Z., 2011. Evergreen broad-leaved forest improves soil water status compared with tea tree plantation in Ailao Mountains, Southwest China. Acta Agriculturæ Scandinavica. Section B, Soil and Plant Science 61, 384-388.

Griffiths, B.S., Donn, S., Neilson, R., Daniell, T.J., 2006. Molecular sequencing and morphological analysis of a nematode community. Applied Soil Ecology 32, 325-337.

Harrison, S., Cornell, H., 2008. Toward a better understanding of the regional causes of local community richness. Ecology Letters 11, 969-979.

Huang, H., Chen, Z., Liu, D., He, G., He, R., Li, D., Xu, K., 2017. Species composition and community structure of the Yulongxueshan (Jade Dragon Snow Mountains) forest dynamics plot in the cold temperate spruce-fir forest, Southwest China. Biodiversity Science Duoyangxing 25, 255-264. (in Chinese)

Kerfahi, D., Tripathi, B.M., Porazinska, D.L., Park, J., Go, R., Adams, 
J.M., 2016. Do tropical rain forest soils have greater nematode diversity than High Arctic tundra? A metagenetic comparison of Malaysia and Svalbard. Global Ecology and Biogeography 25, 716-728.

Lambshead, P.J.D., 2004. Marine Nematode Diversity. In: Chen, Z.X., Chen, S.Y., Dickson, D.W., eds. Nematology: Advances and Perspectives. Volume 1: Nematode Morphology, Physiology and Ecology. Beijing: Tsinghua University Press, pp.438-468.

Lan, G.Y., Hu, Y.H., Cao, M., Zhu, H., Wang, H., Zhou, S.S., Deng, X. B., Cui, J.Y., Huang, J.G., Liu, L.Y., Xu, H.L., Song, J.P., He, Y.C., 2008. Establishment of Xishuangbanna tropical forest dynamics plot: species compositions and spatial distribution patterns. Acta Phytoecologica Sinica 32, 287-298.

Lawton, J.H., Bignell, D.E., Bolton, B., Bloemers, G.F., Eggleton, P., Hammond, M., Hodda, M., Holt, R.D., Larsen, T.B., Mawdsley, N. A., Stork, E., Srivastava, D.S., Watt, A.D., 1998. Biodiversity inventories, indicator taxa and effects of habitat modification in tropical forest. Nature 391, 72-76.

Liang, W., Zhang, X., Li, Q., Jiang, Y., Ou, W., Neher, D.A., 2005. Vertical distribution of bacterivorous nematodes under different land uses. Journal of Nematology 37, 254.

Liu, T., Guo, R., Ran, W., Whalen, J.K., Li, H., 2015. Body size is a sensitive trait-based indicator of soil nematode community response to fertilization in rice and wheat agroecosystems. Soil Biology \& Biochemistry 88, 275-281.

Liu, W.Y., Fox, J.E.D., Xu, Z.F., 2002. Biomass and nutrient accumulation in montane evergreen broad-leaved forest (Lithocarpus xylocarpus type) in Ailao Mountains, SW China. Forest Ecology and Management 158, 223-235.

McSorley, R., Frederick, J.J., 2004. Effect of extraction method on perceived composition of the soil nematode community. Applied Soil Ecology 27, 55-63.

Munch, K., Boomsma, W., Huelsenbeck, J.P., Willerslev, E., Nielsen, R., 2008. Statistical assignment of DNA sequences using Bayesian phylogenetics. Systematic Biology 57, 750-757.

Neher, D.A., 2010. Ecology of plant and free-living soil nematodessoil soil nematodes in natural and agricultural soil. Annual Review of Phytopathology 48, 371-394.

Nielsen, U.N., Ayres, E., Wall, D.H., Li, G., Bardgett, R.D., Wu, T., Garey, J.R., 2014. Global-scale patterns of assemblage structure of soil soil nematodessoil soil nematodes in relation to climate and ecosystem properties. Global Ecology and Biogeography 23, 968 978.

Oksanen, J., Guillaume Blanchet, F., Kindt, R., Legendre, P., Minchin, P.R., O'Hara, R.B., Simpson, G.L., Solymos, P., Stevens, M.H.H., Wagner, H., 2010. vegan: Community Ecology Package. R package version 1.17-3.

Porazinska, D.L., Giblin-Davis, R.M., Esquivel, A., Powers, T.O., Sung, W., Kelley Thomas, W., 2010. Ecometagenetics confirms high tropical rainforest nematode diversity. Molecular Ecology 19, 5521-5530.

Porazinska, D.L., Giblin-Davis, R.M., Powers, T.O., Kelley Thomas, W., 2012. Nematode spatial and ecological patterns from tropical and temperate rainforests. PLoS One 7, e44641.

Powers, T.O., Neher, D.A., Mullin, P., Esquivel, A., Giblin-Davis, R.M., Kanzaki, N., Stock, S.P., Mora, M.M., Uribe-Lorio, L., 2009.
Tropical nematode diversity: vertical stratification of nematode communities in a Costa Rican humid lowland rainforest. Molecular Ecology 18, 985-996.

Procter, D.L.C., 1984. Towards a biogeography of free- living soil soil nematodessoil soil nematodes. I. Changing species richness, diversity and densities with changing latitude. Journal of Biogeography 11, 103-117.

Qiao, N., Schaefer, D., Blagodatskaya, E., Zou, X., Xu, X., Kuzyakov, Y., 2014. Labile carbon retention in forest soils compensates for $\mathrm{CO}_{2}$ released by priming. Global Change Biology 20, 1943-1954.

Quast, C., Pruesse, E., Yilmaz, P., Gerken, J., Schweer, T., Yarza, P., Peplies, J., Glöckner, F.O., 2013. The SILVA ribosomal RNA gene database project: improved data processing and web-based tools. Nucleic Acids Research 41, 590-596.

R Development Core Team, 2013. R: a Language and Environment for Statistical Computing. R Foundation for Statistical Computing. Austria: Vienna

Salame, L., Glazer, I., 2015. Stress avoidance: vertical movement of entomopathogenic nematodes in response to soil moisture gradient. Phytoparasitica 43, 647-655.

Song, D., Pan, K., Tariq, A., Sun, F., Li, Z., Sun, X., Zhang, L., Olusanya, O.A., Wu, X., 2017. Large-scale patterns of distribution and diversity of terrestrial soil nematodessoil soil nematodes. Applied Soil Ecology 114, 161-169.

van den Hoogen, J., Geisen, S., Routh, D., Ferris, H., Traunspurger, W., Wardle, D.A., de Goede, R.G.M., Adams, B.J., Ahmad, W., Andriuzzi, W.S., Bardgett, R.D., Bonkowski, M., Campos-Herrera, R., Cares, J.E., Caruso, T., de Brito Caixeta, L., Chen, X.Y., Costa, S.R., Creamer, R., da Cunha Castro, J.M., Dam, M., Djigal, D., Escuer, M., Griffiths, B.S., Gutiérrez, C., Hohberg, K., Kalinkina, D., Kardol, P., Kergunteuil, A., Korthals, G., Krashevska, V., Kudrin, A.A., Li, Q., Liang, W., Magilton, M., Marais, M., Martín, J. A.R., Matveeva, E., Mayad, E.H., Mulder, C., Mullin, P., Neilson, R., Nguyen, T.A.D., Nielsen, U.N., Okada, H., 2019. Soil nematode abundance and functional group composition at a global scale. Nature 572, 194-198.

Wen, H.D., Lin, L.X., Yang, J., Hu, Y.H., Cao, M., Liu, Y.H., Lu, Z.Y., Xie, Y.N., 2018. Species composition and community structure of a $20 \mathrm{hm} 2$ plot of mid-mountain moist evergreen broad-leaved forest on the Mts.Ailaoshan, Yunnan Province, China. Acta Phytoecologica Sinica 42, 419-429.

Willig, M.R., Kaufman, D.M., Stevens, R.D., 2003. Latitudinal gradients of biodiversity: pattern, process, scale and synthesis. Annual Review of Ecology, Evolution, and Systematics 34, 273309.

Witman, J.D., Etter, R.J., Smith, F., 2004. The relationship between regional and local species diversity in marine benthic communities: A global perspective. Proceedings of the National Academy of Sciences of the United States of America 101, 15664-15669.

Wu, T., Ayres, E., Bardgett, R.D., Wall, D.H., Garey, J.R., 2011. Molecular study of worldwide distribution and diversity of soil animals. Proceedings of the National Academy of Sciences of the United States of America 108, 17720-17725.

Xia, S.W., Chen, J., Shaefer, D., Detto, M., 2015. Scale-dependent soil macronutrient heterogeneity reveals effects of litterfall in a tropical rainforest. Plant and Soil 391, 51-61. 
Xiao, H.F., Tian, Y.H., Zhou, H.P., Ai, X.S., Yang, X.D., Schaefer, D.A., 2014. Intensive rubber cultivation degrades soil nematode communities in Xishuangbanna, southwest China. Soil Biology \& Biochemistry 76, 161-169.

Yeates, G.W., 1999. Effects of plants on nematode community structure. Annual Review of Phytopathology 37, 127-149.

Yeates, G.W., Bongers, T., de Goede, R.G.M., Freckman, D.W., Georgieva, S.S., 1993. Feeding habits in soil nematode families and genera- an outline for soil ecologists. Journal of Nematology 25, 315-331.

Zhang, H., Wang, K., Xu, X., Song, T., Xu, Y., Zeng, F., 2015. Biogeographical patterns of biomass allocation in leaves, stems, and roots in China's forests. Scientific Reports 5, 15997.

Zheng, Z., Feng, Z., Cao, M., Li, Z., Zhang, J., 2006. Forest structure and biomass of a tropical seasonal rain forest in Xishuangbanna, Southwest China. Biotropica 3, 318-327. 